\title{
DETECTION OF THE LOW DENSITY LIPOPROTEIN RECEPTOR GENE PVUII INTRON 15 POLYMORPHISM USING THE POLYMERASE CHAIN REACTION: ASSOCIATION WITH PLASMA LIPID TRAITS IN HEALTHY MEN AND WOMEN
}

\author{
V. GUDNASON*, T. ZHOU ${ }^{*}$, K. THORMAR*, S. BAEHRING ${ }^{*}$, J. COOPER ${ }^{\ddagger}$, G. MILLER ${ }^{\star}$, S.E. \\ HUMPHRIES**, H. SCHUSTER ${ }^{*}$ \\ *Division of Cardiovascular Genetics, Department of Medicine, UCL Medical School, The Rayne \\ Institute, University Street, London WCIE 6JJ

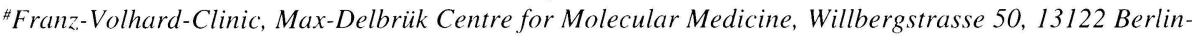 \\ Buch, Germany \\ ${ }^{*}$ MRC Epidemiology and Medical Care Unit, Wolfson Institute of Preventive Medicine, St Bartholomews \\ and the Royal London school of Medicine, Charterhouse Square, London ECIM $6 B Q$
}

\section{SUMMARY}

We have used anchored PCR to amplify and sequence 1400bp of the 15th intron of the Low Density Lipoprotein (LDL) receptor gene, and have determined oligonucleotides and conditions for the genotyping of the previously reported PvuII polymorphism. The cutting site (CAGCTG) is created by the transition of a $\mathrm{CpG}$ to a TpG within the sequence CAGCCG at a position roughly $600 \mathrm{bp} \mathrm{5'}$ from the splice acceptor site of exon 16. Genotype was determined in three populationbased samples of healthy individuals. In a group of 318 men and women from Iceland the frequencies of the Intron-15 T (cutting) allele was 0.23 (95\% CI, 0.19-0.28) and was similar in men and women. In two groups of men from England $(n=385)$ and Scotland $(n=320)$, the frequency was similar, being $0.23(0.19-0.27)$ and $0.25(0.22-0.28)$ respectively. Individuals who were homozygous for the $\mathrm{T}$ allele had lower levels of total-cholesterol triglycerides and apolipoprotein $\mathrm{B}$, than those with other genotypes, and in the combined group of UK men this effect reached statistical significance; compared to the $\mathrm{C} / \mathrm{C}$ group, the $\mathrm{T} / \mathrm{T}$ group had $6 \%$ lower cholesterol $(\mathrm{p}=0.02)$ and $15 \%$ lower triglycerides $(\mathrm{p}=0.03)$. The lowering effect associated with the $\mathrm{T} / \mathrm{T}$ genotype was greater in men who were in the lowest tertile of body mass index $\left(<25 \mathrm{~kg} / \mathrm{m}^{2}\right)$ and for the trait of apoB levels, this genotype $\mathrm{x}$ obesity interaction was statistically significant $(\mathrm{p}=0.01)$. We thus confirm the association between this allele and lower levels of plasma lipid levels previously reported. The availability of a PCR-based method to detect this polymorphism will facilitate further investigation of the impact of LDL-receptor gene variation in determining lipid levels.

KEY WORDS LDL-receptor gene PvuII RFLP Cholesterol.

Correspondence to: S.E. Humphries, Division of Cardiovascular Genetics, Department of Medicine, UCL Medical School, The Rayne Institute, University Street, London WC1E 6JJ, UK. Tel. 44171380 7962; fax. 44171209 6212; e-mail rmhaseh@ucl.ac.uk 


\section{INTRODUCTION}

The LDL-receptor plays a major role in the removal of LDL-cholesterol particles from the blood (Goldstein and Brown, 1989), and many mutations in the LDL receptor gene have been reported that destroy receptor function and cause the disorder Familial Hypercholesterolaemia (FH) (Hobbs et al., 1992, Day et al., 1997). Patients who are carriers for such mutations have plasma cholesterol levels that are elevated twofold or more above normal levels (Goldstein and Brown, 1989) and are at elevated risk of developing atherosclerosis and Ischaemic Heart Disease (IHD) at an early age (Betteridge et al., 1991). Carriers for such mutations are believed to occur at a frequency of 1/500 members of the general population (Goldstein and Brown, 1989).

It is plausible that there may also be mutations in the gene that have only a mild effect on receptor function, and thus cause only a moderate difference in plasma levels in carriers. These mutations could be at any level of receptor regulation or activity. If such mutations were common they would be having a significant effect on determining plasma lipid levels of the overall population. An example of common mutations of mild effect on plasma lipid levels are those producing the isoforms of the apoE protein (Weisgraber et al., 1981), which explain up to 5\% of population variance in LDLcholesterol (Davignon et al., 1988).

So far, only one common mutation altering an amino acid in the LDL receptor has been reported. This is an Alanine to Threonine change at position 370 (A370T), with the T370 allele occurring at a frequency of roughly 0.05 in European Caucasian populations (Kotze et al., 1986, Taylor et al., 1988, Gudnason et al., 1995). This mutation does not cause FH, but there is some evidence that it may be associated with a small effect on plasma LDL cholesterol levels (Gudnason et al., 1989). Four studies have reported that a PvuII polymorphism located in intron 15 of the LDL receptor gene is associated with differences in LDL cholesterol levels (Pederson et al., 1988, Pederson et al., 1989, Schuster et al., 1990, Humphries et al., 1991). The frequency of the PvuII cutting allele is roughly 0.27 in Caucasian populations and those homozygous for the cutting allele, had 10-20\% lower levels of LDL cholesterol in studies of non-FH individuals from Norway (Pederson et al., 1988, Pederson et al., 1989), Germany (Schuster et al., 1990), and Italy (Humphries et al., 1991), although, no effect was seen in a group of individuals from the UK (Taylor et al., 1988) nor from Denmark (Klausen et al., 1993). The PvuII polymorphism is not likely to be functional in itself, but possibly serves as a marker linked to another variation in the gene that either structurally alters the receptor and its activity, or alters its function in a regulatory manner.

Until recently, the PvuII polymorphism has only been detectable using Southern blotting methods, although a PCR-based method has been devised for long PCR (du Plessis and Kotze, 1996), but this is inconvenient for examination in larger samples. Intron 15 is large (roughly $5 \mathrm{~kb}$ ) and has been difficult to amplify. Only a partial sequence of intron 15 is available (Hobbs et al., 1985), but from Southern blotting experiments (Humphries et al., 1985) the location of the PvuII site was known to be about $900 \mathrm{bp}$ from the 3 ' end of exon 16 . We report here a partial sequence of the intron which has enabled an easily applied PCR method for detection of this polymorphism to be developed. 


\section{MATERIALS AND METHODS}

\section{Subjects}

Three groups of individuals were studied, the first from Iceland comprising 318 healthy men and women (mean age 45 years) selected from a dietary survey (Sigurdsson et al., 1992). Individuals reporting evidence of IHD or with FH, diabetes or taking lipid lowering medication were excluded, and full details of the characteristics of this group have been published previously (Sigurdsson et al., 1992). The second and third groups were healthy middle-aged men (mean age 56 years) selected from a general practice in the South of England (Camberley) and another in Scotland (St. Andrew's). All were free of symptoms of IHD and their mean ( \pm SD) body mass index (BMI) was $26.5 \pm 3.7 \mathrm{~kg} / \mathrm{m}^{2}$ (Miller et al., 1996). Plasma lipids were measured using standard techniques as reported (Sigurdsson et al., 1992, Miller et al., 1996). Serum apolipoprotein B (apoB) was measured by an automated immunoturbidometric method with reagents from Incstar/Sorin (Wokingham Berks, UK) for the UK sample and with reagents from Roche MA 30: Cobas Mira for the Icelandic sample. The different source of reagents and standards explains the difference in mean levels of apoB between the two samples.

\section{Long Chain PCR}

The entire intron 15 was amplified with the following primers previously published (Hobbs et al., 1992): 5'-exon 15 primer: 5'-GAA GGG CCT GCA GGC ACG TGG CAC T-3' and 3' exon 16 primer: 5'-CGC TGG GGG ACC GGC CCG CGC TTA C-3'. 50 ng of genomic DNA was used in a PCR reaction containing $200 \mathrm{M}$ of each dNTP, 10 pmol of each primer, $5 \mathrm{U}$ Taq polymerase (Perkin-Elmer, USA) and $5 \mathrm{U}$ Taq extender (Stratagene, USA) in a total volume of $100 \mu \mathrm{l}$ of the extender buffer provided by the manufacturer. The PCR conditions were as follows: hot start $94^{\circ} \mathrm{C}$ for $2 \mathrm{~min}$ and subsequently 30 cycles of $94^{\circ} \mathrm{C}$ for 15 seconds, $65^{\circ} \mathrm{C}$ for 30 seconds, $70^{\circ} \mathrm{C}$ for $5 \mathrm{~min}$ and finally $72^{\circ} \mathrm{C}$ for $10 \mathrm{~min}$. Digestion of PCR was performed as described in the genotyping protocol.

\section{Anchored PCR and Sequencing}

To amplify a smaller 3' subfragment containing the PvuII restriction site, 30 different primers available in the laboratory from other projects were used as forward primers, while the 3'-exon 16 primer was used as reverse primer, in separate reactions. 1ng of the expected $5 \mathrm{~kb}$ long chain PCR amplification product comprising exon 15, intron 15 and exon 16 was used under low stringency conditions to get amplification products using the same PCR reaction mix as described for the genotyping protocol. With the 3'-exon 13 LDL receptor primer (5'-GTT TCC ACA AGG AGG TTT CAA GGT T-3',) (Hobbs et al 1992) a $1.4 \mathrm{~kb}$ fragment was detected after electrophoresis in a $0.8 \%$ agarose gel. After purifying the amplification product from the gel, a booster PCR was performed using the same conditions to confirm specificity of the amplification product. Subsequently, the existence of the PvuII site was confirmed by restriction analysis. Direct sequencing was performed using a standard protocol as described before (Schuster et al., 1995). 


\section{DNA isolation and genotyping}

DNA was isolated using a salting out method (Miller, 1988). PvuII genotype was determined amplifying a part of intron 15 of the LDL receptor gene using 10 pmol of each of the following primers: $5^{\prime}$ - primer: $5^{\prime}$-TCC CCT TCA AAA TGC CCT CTT-3' and 3' -primer: 5'-AGC CAC CGA GCC CAG CCT AAG AA-3' with 50 ng of genomic DNA and $0.75 \mathrm{U}$ of Taq polymerase (Gibco, UK) in a total volume of $20 \mu \mathrm{l}$ of the buffer recommended by the manufacturer containing $4.1 \mathrm{mM} \mathrm{MgCI}_{2}, 200 \mathrm{M}$ each dNTP. The PCR conditions were as follows: $94^{\circ} \mathrm{C}$ for $5 \mathrm{~min}, 63^{\circ} \mathrm{C}$ for $3 \mathrm{~min}$ and $70^{\circ} \mathrm{C}$ for 3 min once and subsequently for 30 cycles of $94^{\circ} \mathrm{C}$ for $1 \mathrm{~min}, 63 \mathrm{C}$ for $1 \mathrm{~min}$ and at $70^{\circ} \mathrm{C}$ for 2 and a half min, and finally at $70^{\circ} \mathrm{C}$ for 10 minutes. Digestion of PCR product was performed by addition of $5 \mathrm{U}$ of PvuII (Boehringer) to $10 \mu \mathrm{l}$ of the PCR product in the buffer recommended by the manufacturer and incubated at $37^{\circ} \mathrm{C}$ for 4 hours. The product was run on a $2 \%$ agarose gel and the bands visualised by ethidium bromide and viewing on a UV trans-illuminator.

\section{Statistical analysis}

The relationship between genotype and levels of plasma lipid traits was examined by ANOVA after adjustment for age and body mass index (BMI) using multiple linear regression. The characteristics (weight, height, age and plasma lipids) of the two groups of men from the UK were very similar (none significantly different) and analysis was carried out in the combined group. The frequency of the genotype groups compared to that expected for Hardy Weinberg properties was analysed by a $\mathrm{X}^{2}$ test. To analyse potential interaction with BMI, individuals were coded 0,1 , or 2 according to their tertile of BMI and this was included as a factor in a two-way ANOVA, after adjustment for age. Analysis was carried out using SPSS PC analytical package. Statistical significance was taken at a level of $\mathrm{p}=0.05$.

\section{RESULTS}

Initial attempts were made to amplify the entire intron using a forward primer flanking exon 15 at the 5 ' end and a reverse primer flanking exon 16 at the 3 ' end using a long chain PCR protocol (data not shown). Several random primers available in the laboratory were then separately used as forward primers in conjunction with the exon 16 reverse primer to amplify DNA from individuals homozygous for the lack of the cutting site and heterozygous for the cutting site, as determined by previous Southern blotting experiments. Figure 1a illustrates the location of the forward primer with sufficient sequence homology to intron sequence to allow a successful amplification of an anchored PCR fragment (upper panel). As shown in Figure $1 \mathrm{~b}$, this resulted in the amplification of a fragment approximately $1400 \mathrm{bp}$, which was cleaved into two fragments of roughly 900 bp and $500 \mathrm{bp}$.

Further sequencing of this $1400 \mathrm{bp}$ fragment was carried out to determine the exact location and sequence change creating the PvuII site. Figure 2 shows the sequence determined from an individual heterozygous for the cutting site, with a $\mathrm{C}$ to $\mathrm{T}$ transition within the sequence CAGCCG which would create the cutting site 3' CAGCTG. No other sequence differences were seen in this fragment of over 900 bases. The part of the 
A

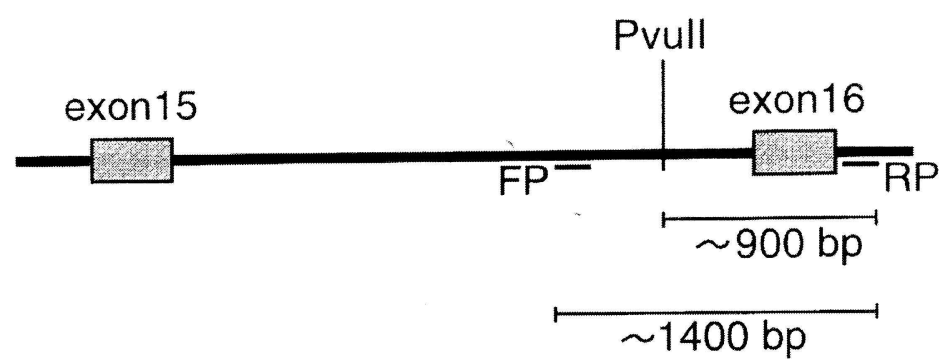

B

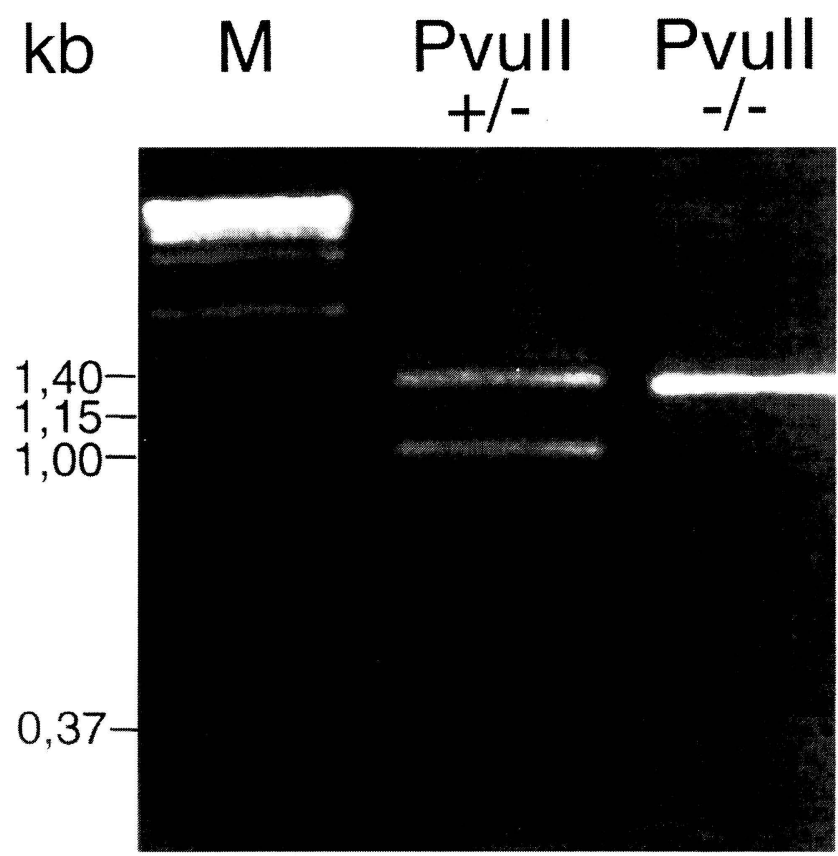

Figure 1. a) Map of the intron 15-16 region of the LDL-receptor gene, showing the appropriate location of the Pvull site and the primers used. b) $2 \%$ Agarose gel showing M, marker of primers used DNA digested with HindIII, Pvu +/- and Pvu -/-. Amplified DNA from individuals of known PvuII genotype, digested with PvuII and run as described in Materials and Methods.

sequence obtained was used to synthesise a reverse primer, which was used for subsequent genotyping. As shown in Figure 3, the result is amplification of a fragment of roughly $800 \mathrm{bp}$ which is cleaved by PvuII digestion into fragments of around $600 \mathrm{bp}$ and $200 \mathrm{bp}$. The figure shows that the presence of the cutting site (T allele) is inherited in the expected manner in a small nuclear family. The genotypes obtained with this method were consistent with genotypes previously obtained by Southern blotting (not shown). 


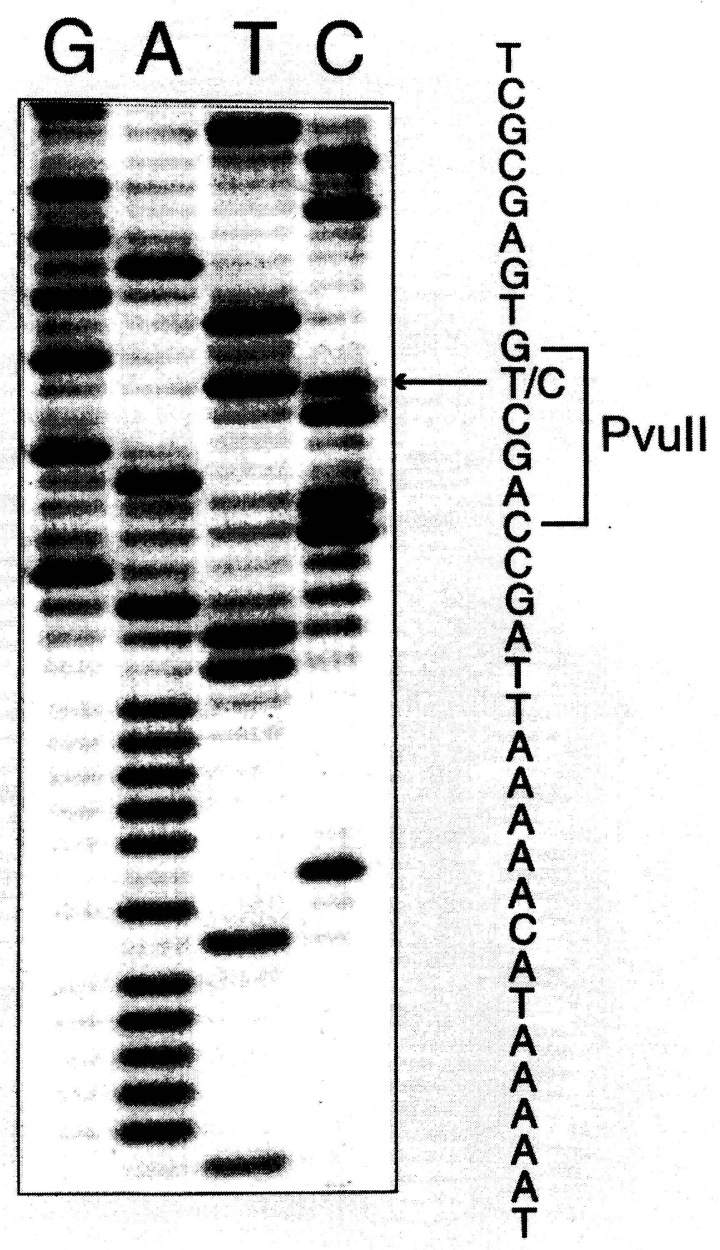

Figure 2. Sequence of the part of intron 15 containing the PvuII site from an individual heterozygous for the site.

Genotype was next determined in three groups of healthy men and women from Iceland, England and Scotland. For all samples genotype distribution was not different from that expected for Hardy Weinberg proportions. The estimated frequencies of the T allele and $95 \%$ confidence intervals of the estimates are shown in Table 1. These range between $0.21-0.24$, and none are significantly different from each other.

The relationship between C/T genotype and levels of total cholesterol, apo B and plasma triglycerides was examined separately in the men and women from Iceland and in the combined groups of men from the UK. As shown in Table 2, plasma cholesterol, triglyceride and apo B levels were consistently lower in those homozygous for the T allele except for cholesterol in Icelandic women, compared to other genotype groups, 


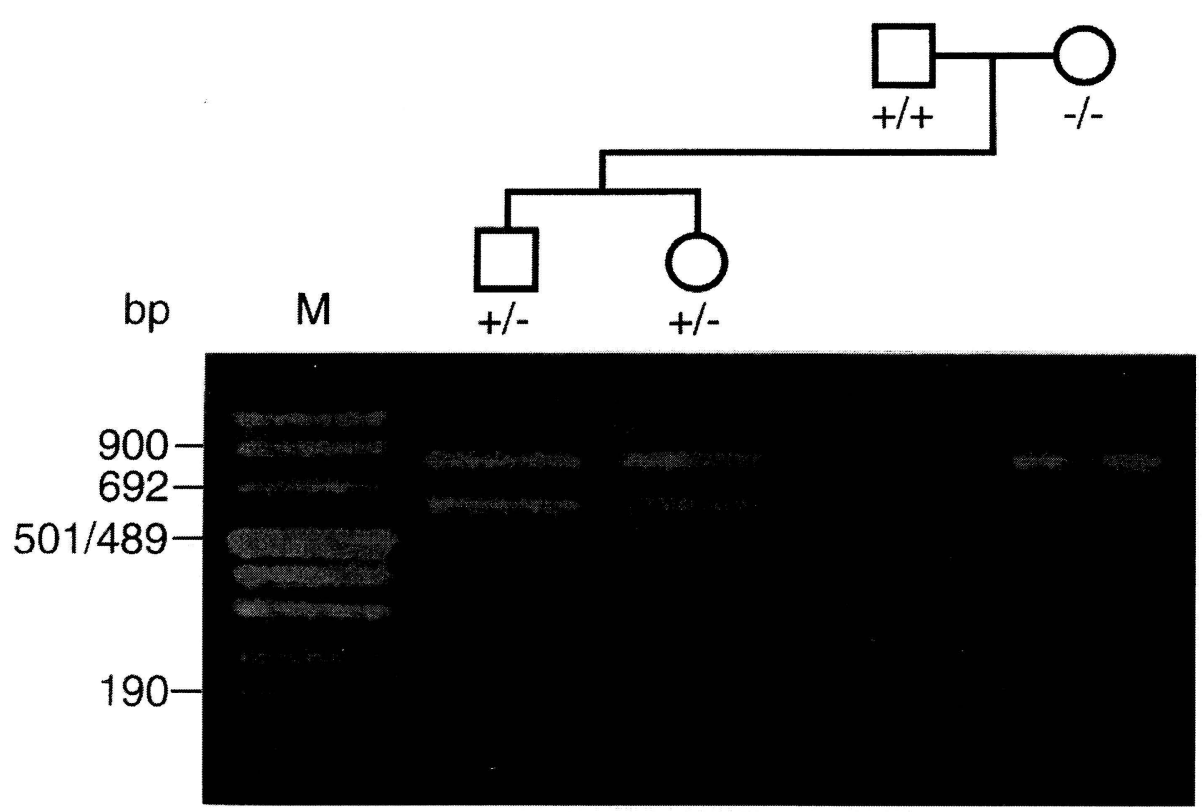

Figure 3. PvuII genotype from four individuals from a small nuclear family, using conditions as described in Materials and Methods.

Table 1. Estimated $\mathrm{T}$ allele frequency and $95 \%$ confidence intervals in the samples studied.

\begin{tabular}{lcc}
\hline Sample & Number & Frequency of T allele (95\% CI) \\
\hline Iceland men & 152 & $0.234(0.19-0.28)$ \\
Iceland women & 166 & $0.253(0.21-0.30)$ \\
England men & 385 & $0.228(0.19-0.27)$ \\
Scotland men & 320 & $0.250(0.22-0.28)$ \\
\hline
\end{tabular}

and this effect reached statistical significance in the combined UK group. Data were also analysed in men stratified by tertiles of BMI, and as shown in Figure 4 the genotype effect on cholesterol and apoB was strongest in men below the lower tertile of BMI. This genotype $\mathrm{x}$ BMI interaction was statistically significant for the trait of plasma apoB levels. In the group of Icelandic men and women the lowering effect associated with the $\mathrm{T}$ allele was also larger in those with lower BMI, but this interaction was not statistically significant. For example, in men, compared to the $\mathrm{C} / \mathrm{C}$ group, cholesterol levels for those with one or more T allele were $0.29 \mathrm{mmol} / \mathrm{l}$ lower in those with a BMI below the lowest tertile $\left(<23.3 \mathrm{~kg} / \mathrm{m}^{2}\right)$ but $0.21 \mathrm{mmol} / \mathrm{l}$ higher in those above the highest tertile $\left(>25.8 \mathrm{~kg} / \mathrm{m}^{2}\right)$. 
Table 2. Plasma lipid traits (mean $\pm(S E)$ ) in subjects with different Pvull genotypes

\begin{tabular}{|c|c|c|c|c|}
\hline \multirow[t]{2}{*}{ Sample } & \multirow[t]{2}{*}{ Trait } & \multicolumn{3}{|c|}{ Pvull genotype } \\
\hline & & $\mathrm{C} / \mathrm{C}$ & $\mathrm{C} / \mathrm{T}$ & $\mathrm{T} / \mathrm{T}$ \\
\hline & & $\mathrm{N}=89$ & $\mathrm{~N}=55$ & $\mathrm{~N}=8$ \\
\hline \multirow[t]{4}{*}{ Iceland men } & Chol(mmol/l) & $5.59(0.11)$ & $5.60(0.16)$ & $5.33(0.18)$ \\
\hline & Trig*(mmol/l $)$ & $1.23(0.54-2.44)$ & $1.13(0.56-2.08)$ & $1.08(0.63-1.93)$ \\
\hline & ApoB $(g / l)$ & $1.21(0.03)$ & $1.20(0.04)$ & $1.15(0.04)$ \\
\hline & & $\mathrm{N}=96$ & $\mathrm{~N}=56$ & $\mathrm{~N}=14$ \\
\hline \multirow[t]{4}{*}{ Iceland women } & $\mathrm{Chol}(\mathrm{mmol} / \mathrm{l})$ & $5.57(0.14)$ & $5.42(0.13)$ & $5.40(0.33)$ \\
\hline & Trig*(mmol/l $)$ & $0.98(0.45-1.92)$ & $0.92(0.50-1.56)$ & $0.83(0.37-1.53)$ \\
\hline & ApoB $(g / l)$ & $1.14(0.03)$ & $1.11(0.03)$ & $1.04(0.08)$ \\
\hline & & $N^{\#}=396$ & $\mathrm{~N}=245$ & $\mathrm{~N}=46$ \\
\hline \multirow[t]{3}{*}{ UK men } & $\operatorname{Chol}(\mathrm{mmol} / \mathrm{l})$ & $5.79(0.05)$ & $5.83(0.07)$ & $5.44(0.14)^{1}$ \\
\hline & Trig* $(\mathrm{mmol} / \mathrm{l})$ & $1.78(1.69-1.87)$ & $1.83(1.70-1.96)$ & $1.51(1.31-1.72)^{2}$ \\
\hline & ApoB $(g / l)$ & $0.88(0.01)$ & $0.89(0.02)$ & $0.85(0.05)^{3}$ \\
\hline
\end{tabular}

$*(95 \%, \mathrm{CI})$

\#Small discrepencies between number of subjects in table 1 and 2 are because of 8 men where complete lipid data was not avaiable

'Overall by AVOVA $\mathrm{p}=0.07, \mathrm{CC} \vee \mathrm{TT} \mathrm{p}=0.02$;

${ }^{2}$ Overall by AVOVA $\mathrm{p}=0.07, \mathrm{CC} \vee \mathrm{TT} \mathrm{p}=0.03$;

${ }^{3}$ Overall by AVOVA $\mathrm{p}=0.77 \mathrm{CC}$ v TT $\mathrm{p}=0.52$.

\section{DISCUSSION}

Although previous studies (Pederson et al., 1988, Pederson et al., 1989, Schuster et al., 1990, Humphries et al., 1991) have shown an association between the PvuII + cutting site (the Intron 15-T allele) and lower levels of plasma cholesterol, studies from the UK (Taylor et al., 1988) and Denmark (Klausen et al., 1993) failed to detect a significant effect. Several possible reasons for this discrepancy can be proposed. Firstly, the original three studies could be showing an association by chance alone, but this is statistically unlikely. Secondly, the original studies used unaffected relatives (mainly spouses) of patients with FH, where PvuII genotyping had been carried out as part of co-segregation studies. Such samples are clearly not truly representative of the general population and there may have been some underlying genetic or environmental bias in the sample. For example, it has been suggested (Klausen et al., 1993) that the group of relatives lacking the cutting site (genotype $\mathrm{C} / \mathrm{C}$ ) may have included some individuals with $\mathrm{FH}$, and the higher levels of plasma cholesterol of these individuals would thus elevate the estimate of the whole genotype group, giving a larger difference between the $\mathrm{C} / \mathrm{C}$ and $\mathrm{T} / \mathrm{T}$ groups. Alternatively, the relatives of patients with FH may have adopted a lipid-lowering diet or life style which would magnify any small effect associated with the PvuII genotype. 

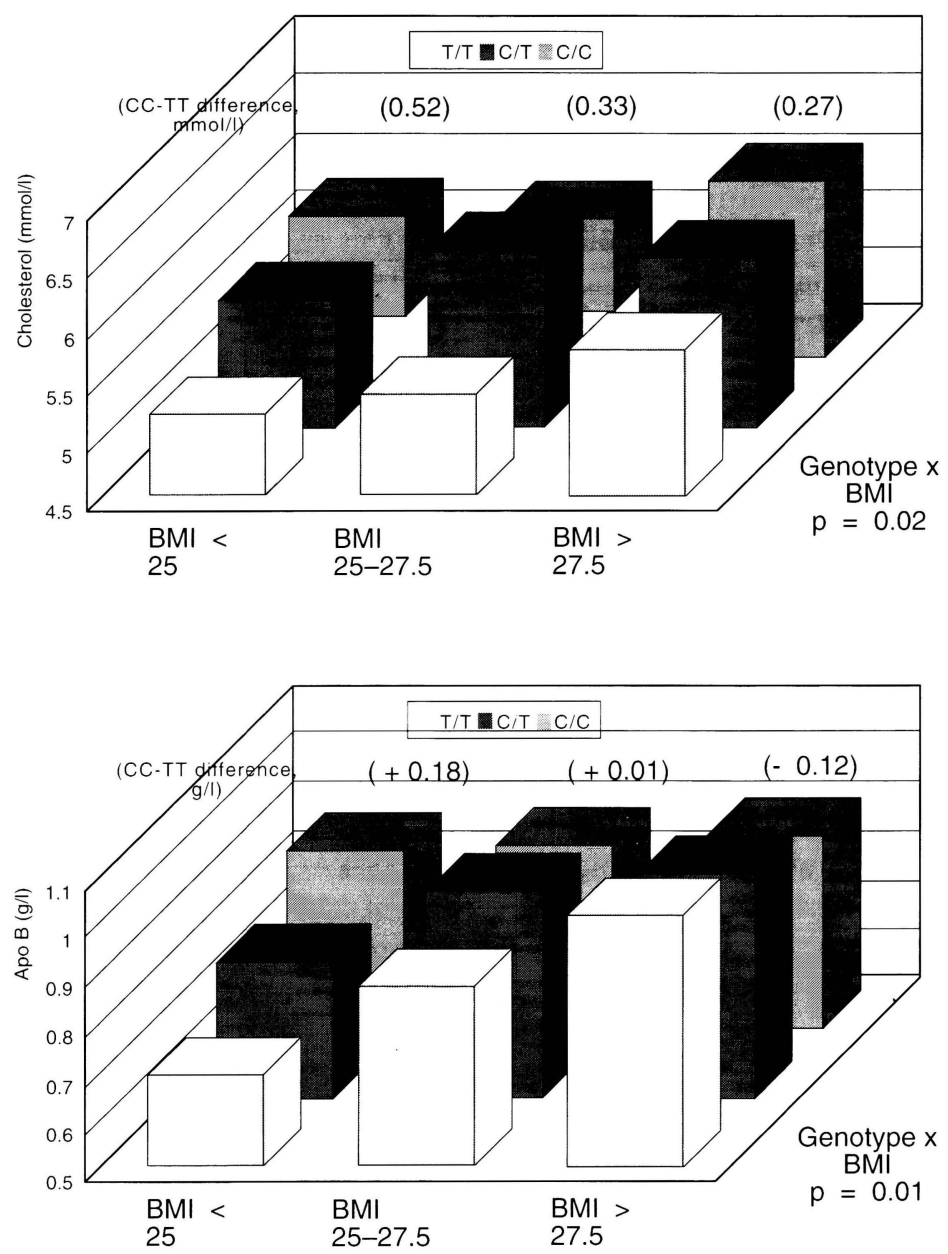

Figure 4. Mean cholesterol ( $\mathrm{mmol} / \mathrm{l})$ and $\operatorname{apoB}(\mathrm{g} / \mathrm{l})$ levels in the UK men with different LDL-receptor PvuII genotype, divided by tertile of Body Mass Index

Such environmental effects would be absent in a representative sample of the general population, which was examined in the Danish study.

In this study we have detected a small but consistent association between the LDLreceptor intron 15 PvuII cutting allele $(\mathrm{T})$ and lower levels of plasma lipid traits in samples of healthy men and women representative of the general population in Iceland and in the UK. There was no gene-dosage effect of the PvuII polymorphism on any of the traits seen in the UK men, which is similar to that seen in some other studies of the PvuII polymorphism (Pederson et al., 1989), and the effect is apparent only in those homozygous for the T allele, who, compared to those with the CC genotype, have levels (in men) of total cholesterol 5-6\% lower, triglycerides 12-15\% lower and apoB 3-5\% lower. In the sample of women, although non significant, the effects were of similar size, being $2.7 \%, 15.3 \%$ and $8 \%$ lower respectively. The size of the lowering effect associated with 
the T/T genotype in these samples of healthy individuals is roughly half that reported previously, and was only significant in the large sample of men from the UK. In part because of the rapid PCR-based genotyping method, the size of the present sample is at least twice as large as has been examined previously (eg 170 men in the Danish study) and allowed the detection of a small effect. Roughly $5 \%$ of individuals in Iceland and the UK will be homozygous for the $T$ allele and thus at a population level the plasma lipidlowering effect associated with this genotype is small $\left(\mathrm{R}^{2}\right.$ for cholesterol in the UK men was $<1 \%$, not shown). However, the effect was larger in healthy individuals who were thin, $\left(\mathrm{BMI}<25 \mathrm{~kg} / \mathrm{m}^{2}\right)$ and this may explain in part the failure to detect the association in the Danish study, where the mean BMI was $25 \mathrm{~kg} / \mathrm{m}^{2}$ (Hansen et al., 1993) and no stratification for BMI was used. It is possible that the reason for the lack of a significant effect of the PvuII genotype on plasma lipoprotein levels in the Icelandic sample may in part be related to the average BMI in the Icelandic group, which is $25.4 \mathrm{~kg} / \mathrm{m}^{2}$, in men. Although the difference in plasma cholesterol and apoB levels was not statistically significant between those homozygous for a $\mathrm{C}$ allele and those homozygous for a $\mathrm{T}$ allele, the trend was observed in those below a BMI of $25 \mathrm{~kg} / \mathrm{m}^{2}(+2.8 \%$ and $+4.6 \%$ respectively).

Berg and colleagues have reported a potential interaction between variation in the apo E gene (E2, E3 and E4 isoforms) and the LDL receptor PvuII genotype in determining plasma lipid levels (Pederson et al., 1989). In the samples examined here apo E genotype was strongly associated with plasma lipid levels as expected for the Icelandic sample (Gudnason et al., 1993), and for the UK samples (Day, Bolla, Humphries and Miller, unpublished). However, because the LDL-receptor genotype lipid lowering effect was only seen in the smallest $\mathrm{T} / \mathrm{T}$ group ( $\mathrm{n}=45$ in the UK men) no analysis for interaction with apoE was attempted.

Although first reported in 1988 (Pederson et al., 1988), the mechanism of this association is currently unknown. The intron $15 \mathrm{C} / \mathrm{T}$ change is unlikely to be of functional significance itself, but is probably an allelic marker for a functional sequence elsewhere at the gene locus with the $\mathrm{T}$ allele being a marker for a sequence change that results in greater numbers of LDL-receptors on the cell surface of a higher LDL receptor, activity or stability. In those with the genotype T/T this would have the result of improved clearance of both apoE (eg VLDL remnants) and apoB (eg LDL) containing lipoproteins, leading to lower plasma levels of triglycerides, cholesterol and apoB. The observation that this genotype effect is confined to those homozygous for the T allele, and is enhanced in those with low BMI needs confirmation in a larger study, and the possible molecular mechanisms of these effects is unclear.

The availability of a convenient PCR method for determining PvuII genotype will enable further studies to be carried out to confirm and extend these observations, and cell and molecular biology studies are also warranted to determine the mechanism of the lowering effect. The polymorphism will also be of use in tracing the LDL receptor gene in families with $\mathrm{FH}$.

\section{ACKNOWLEDGEMENTS}

This work was supported by grants from the British Heart Foundation and the MRC and by a grant-in-aid to H. Schuster from the Deutsche Forchungsgemeinschaft in form of a Hess Fellowship. T. Zhou is supported by the Kaiserin-Freidrich-Stiftung and V. 
Gudnason by a grant from the Helen Eppel Foundation. The support of the Icelandic Heart Association and the Icelandic Council of Science is appreciated. We thank Manjeet Bolla and Ian Day for access to unpublished apoE genotype data in the sample of the UK men.

\section{REFERENCES}

Betteridge, D.J., Broome, K., Durrington, P.N., Mann, J.I., Miller, J.P., Neil, H.A.W., Thompson, G.R., Thorogood, M. (1991). Risk of fatal coronary heart disease in familial hypercholesterolaemia. British Medical Journal, 303, 893-896.

Davignon, J., Gregg, R.E., Sing, C.F. (1988). Apolipoprotein E polymorphism and atherosclerosis. Arteriosclerosis, $\mathbf{8}, 1-21$.

Day, I.N.M., O’Dell, S., Haddad, L., Bolla, M., Whittall, R., Gudnason, V., Humphries, S.E. (1997). Spectrum of mutations in heterozygous familial hypercholesterolaemia: towards molecular diagnostics. Human Mutation, 10, 116-127.

du Plessis, L., Kotze, M.J. (1996). Detection of the PvuII RFLP in intron 15 of the LDL receptor gene by long-distance PCR. Clin. Genet., 49, 277-278.

Goldstein, J.L., Brown, M.S. (1989). Familial Hypercholesterolemia. In C.R. Scriver, A.L. Beaudet, W.S. Sly, D. Valle (Eds.), The Metabolic basis of Inherited Disease. New York: McGraw-Hill Book Co., pp. 1215-1250.

Gudnason. V.. Patel. D.. Sun, X.M., Humphries, S., Soutar, A.K., Knight, B.L. (1995). Effect of the StuI polymorphism in the LDL receptor gene (Ala 370 to Thr) on lipid levels in healthy individuals. Clin. Genet. 47, 68-74.

Gudnason. V.. Sigurdsson. G.. Jr.. Humphries, S., Sigurdsson, G. (1993). Association of apolipoprotein E polymorphism with plasma levels of high density lipoprotein and $\mathrm{Lp}(\mathrm{a})$, and effect of diet in healthy men and women. Nutr. Metabol. Cardiovasc. Dis., 3, 136-141.

Hansen. P.S.. Gerdes, L.U., Klausen, I.C., Gregersen, N., Faergeman, O. (1993). Polymorphisms in the apolipoprotein B-100 gene contributes to normal variation in plasma lipids in 464 Danish men born in 1948. Hum. Genet., 91, 45-50.

Hobbs. H.H., Brown, M.S., Goldstein, J.L. (1992). Molecular genetics of the LDL receptor gene in familial hypercholesterolemia. Hum. Mutat., 1, 445-466.

Hobbs, H.H., Lehrman, M.A., Yamamoto, T., Russell, D.W. (1985). Polymorphism and evolution of Alu sequences in the human low density lipoprotein receptor gene. Proc. Natl. Acad. Sci. USA, 82, 7651-7655.

Humphries, S., Coviello, D.A., Masturzo, P., Balestreri, R., Orecchini, G., Bertolini, S. (1991). Variation in the low density lipoprotein receptor gene is associated with differences in plasma low density lipoprotein cholesterol levels in young and old normal individuals from Italy. Arterioscler. Thromb., 11, 509-516.

Humphries, S.E., Kessling, A.M., Horsthemke, B., Donald, J.A., Seed, M., Jowett, N., Holm, M., Galton, D.J., Wynn, V., Williamson, R. (1985). A common DNA polymorphism of the lowdensity lipoprotein (LDL) receptor gene and its use in diagnosis. Lancet, 1, 1003-1005.

Klausen, I.C., Hansen, P.S., Gerdes, L.U., Rudiger, N., Gregersen, N., Faergeman, O. (1993). A PvuII polymorphism of the low density lipoprotein receptor gene is not associated with plasma concentrations of low density lipoproteins including LP(a). Hum. Genet., 91, 193-195.

Kotze, M.J., Retief, A.E., Brink, P.A., Weich, H.F. (1986). A DNA polymorphism in the human low-density lipoprotein receptor gene. S. Afr. Med. J., 70, 77-79.

Miller, G.J., Bauer, K.A., Barzegar, S., Cooper, J.A., Rosenberg, R.D. (1996). Increased activation of the haemostatic system in men at high risk of fatal coronary heart disease. Thromb. Haemost., 75, 767-771.

Miller, S.A., Dykes, D.D., Polesky, H.F. (1988). A simple salting out procedure for extracting DNA from human nucleated cells. Nucleic Acids Res., 16, 1215 
Pedersen, J.C., Berg, K. (1988). Normal DNA polymorphism at the low density lipoprotein receptor (LDLR) locus associated with serum cholesterol level. Clin. Genet., 34, 306-312.

Pedersen, J.C., Berg, K. (1989). Interaction between low density lipoprotein receptor (LDLR) and apolipoprotein E (apoE) alleles contributes to normal variation in lipid level. Clin. Genet., 35, 331-337.

Schuster, H., Humphries, S., Rauh, G., Held, C., Keller, C., Wolfram, G., Zollner, N. (1990). Association of DNA-haplotypes in the human LDL-receptor gene with normal serum cholesterol levels. Clin. Genet., 38, 401-409.

Schuster, H., Keller, C., Wolfram, G., Zollner, N. (1995). Ten LDL receptor mutants explain one third of familial hypercholesterolemia in a German sample. Arterioscler. Thromb. Vasc. Biol., 15, 2176-2180.

Sigurdsson, G., Jr., Gudnason, V., Sigurdsson, G., Humphries, S.E. (1992). Interaction between a polymorphism of the apo A-I promoter region and smoking determines plasma levels of HDL and apo A-I. Arterioscler. Thromb., 12, 1017-1022.

Taylor, R., Jeenah, M., Seed, M., Humphries, S. (1988). Four DNA polymorphisms in the LDL receptor gene: their genetic relationship and use in the study of variation at the LDL receptor locus. J. Med. Genet., 25, 653-659.

Weisgraber, K.H., Rall, S.C.J., Mahley, R.W. (1981). Human E apoprotein heterogeneity. Cysteine-arginine interchanges in the amino acid sequence of the apoE isoforms. J. Biol. Chem., 256, 9077-9083. 


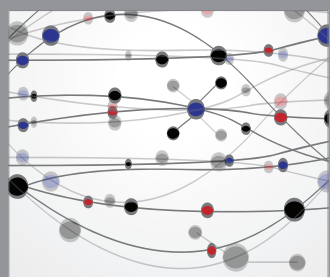

The Scientific World Journal
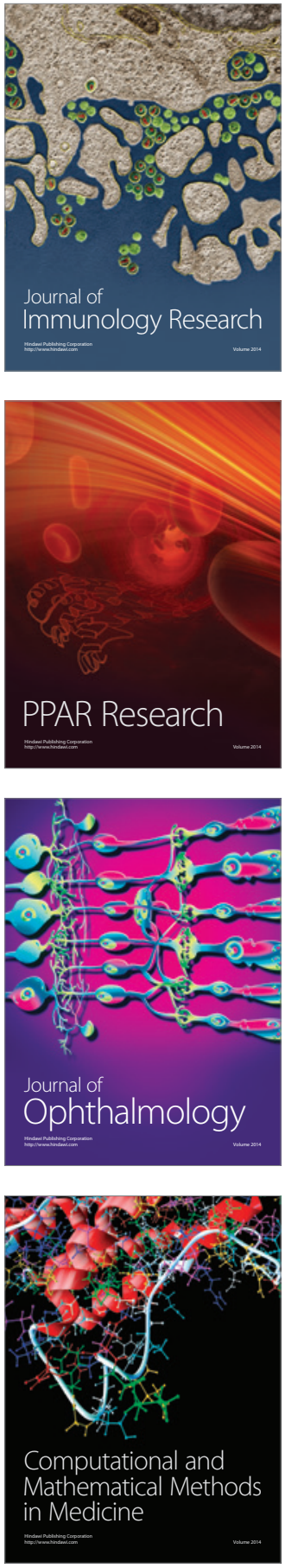

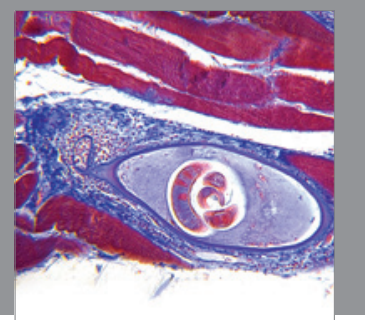

Gastroenterology

Research and Practice
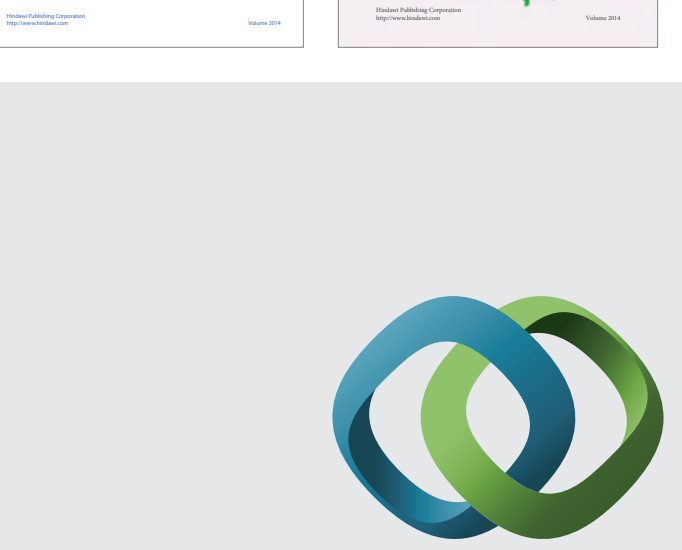

\section{Hindawi}

Submit your manuscripts at

http://www.hindawi.com
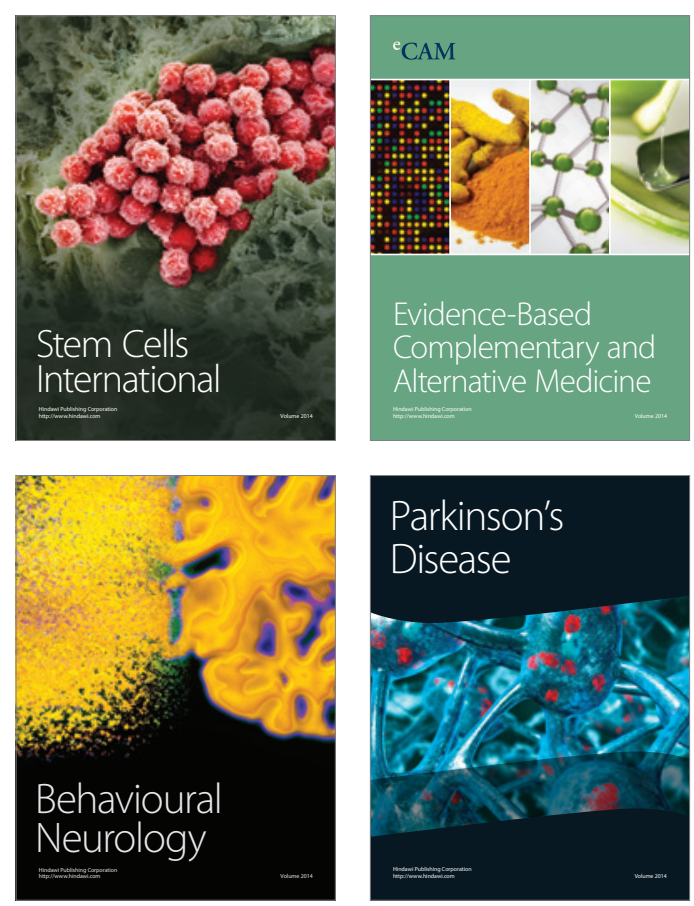

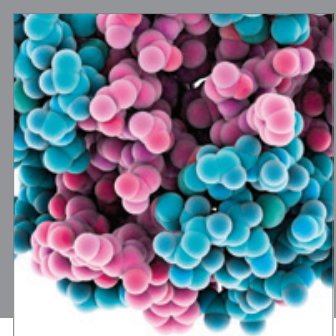

Journal of
Diabetes Research

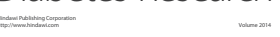

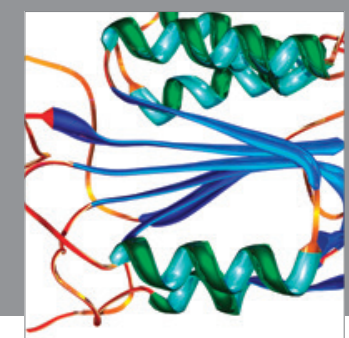

Disease Markers
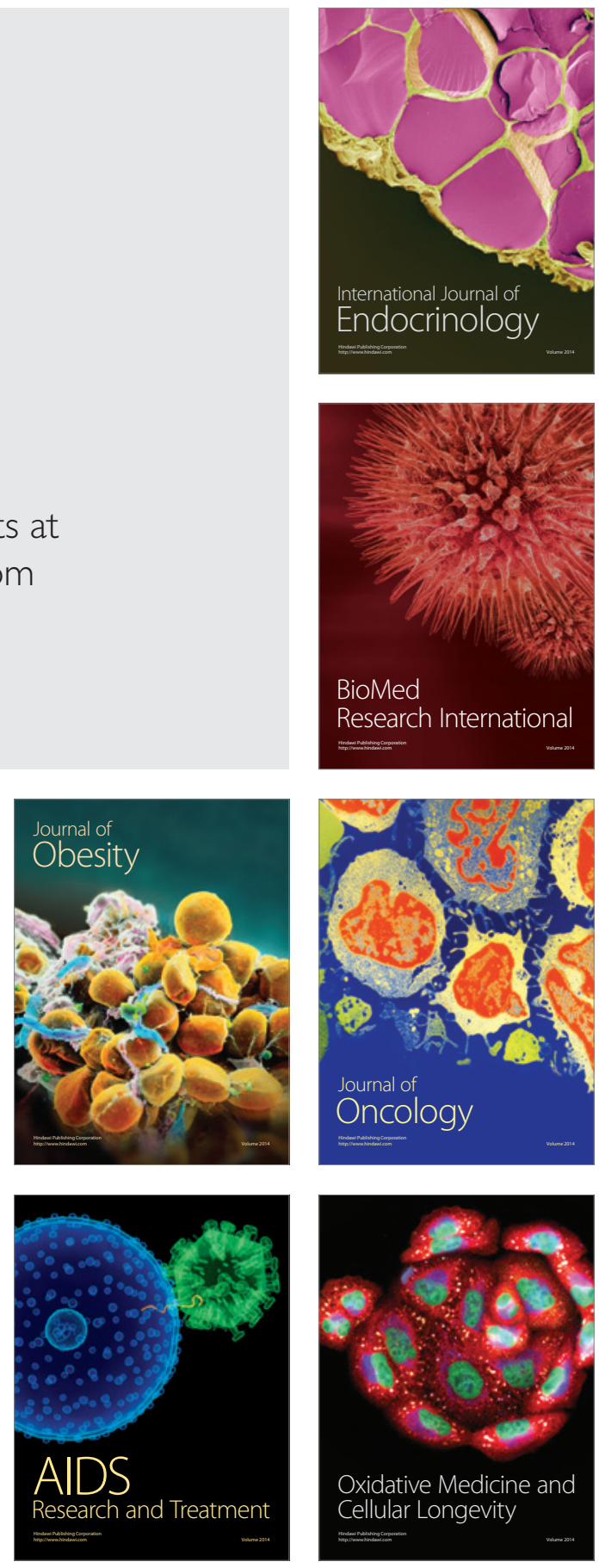